\title{
Tank Structural Fatigue Fracture in Hydrocarbon Transportation
}

\author{
Alexey Pimnev ${ }^{1, *}$, Ruslan Aginey ${ }^{2}$, Svetlana Yakubovskaya $^{1}$, and Mikhail Alexandrov ${ }^{1}$ \\ ${ }^{1}$ Industrial University of Tyumen, 625001 Volodarskogo str. 38, Tyumen, Russia \\ ${ }^{2}$ JSC “Giprogazcentr”, 603005 st. Alexeevskaya 26, Nizhniy Novgorod, Tyumen, Russia
}

\begin{abstract}
The article touches upon the reasons of cracks formation in a vertical steel tank wall used in oil transportation. Here are given the comparative research results of chemical composition and mechanical properties of steel, used in manufacture of the flat product: tensile strength, yield strength, impact strength and hardness.
\end{abstract}

\section{Introduction}

Modern studies have found that fatigue fracture occurs in constructions with a large number of technological and operational defects, which include quench cracks, weld defects, nonmetallic inclusions, pores, corrosion pits, nicks, cuts, scratches, "pittings", the traces of mechanical processing, etc [1,12,15,19-21]. Cyclic loading of vertical steel tanks (VST) leads to accumulation of damages starting with local plastic deformation, resulting in the occurrence of shear bands and micro-cracks, one and in some cases several of which, turns into a main crack leading to ultimate limit state - the destruction of the tank.

Fatigue durability or VST resource means the number of cycles $\mathrm{N}$ which a construction can endure before the occurrence of the limit state. The process of construction cyclic durability consists of two stages; and it can be represented by the following formula:

$$
N=N_{O M}+N_{D C},
$$

where $N_{O M}$ is the number of cycles before the occurrence of micro-cracks - the first stage; this value is determined by the Coffin-Manson Law; a crack of this size typically does not cause section destruction;

$N_{D C}$ is the number of cycles before the development of cracks having a critical size - the second stage; the crack development can be described by the Paris Law.

The design stresses in the VST structural parts reach $0.6 \ldots 0.8$ of yield stress. Under such conditions, the occurrence of local defects, which are stress concentrators, lead to a formation of separate zones, where plastic deformation is so high that micro-cracks occur at a very early stage of loading. Different authors have found that the stage of micro-crack initiation is approximately $10 \%$ of the total number of cycles $\mathrm{N}$.

There are a lot of cases when constructions, e.g. gas holders, having passed the acceptance tests with the load exceeding the estimated one $1.3 \ldots 1.4$ times, have been

\footnotetext{
${ }^{*}$ Corresponding author: pimnev@mail.ru
} 
destroyed after 3...5 years of operation; or during their examination cracks absent earlier were found.

Pressure vessels are very close to tanks by their stress-strain state which is confirmed by studies published by V. L. Berezin, A. G. Gumerov, R. I. Verevkin, etc. Thus we can conclude that qualitatively the picture of fatigue fracture of pressure vessels and tanks should be the same.

Currently, the average "age" of tanks used in Russia is over 30 years, i.e. the lifetime of the main part of the tanks has exceeded the standard. Therefore, we can assume that fatigue cracks in constructive elements of these tanks have already been initiated.

\section{The Object of Study}

For experimental research a vertical steel tank VST-20000, constructed in 1988 at a midstream operations pump station, was selected. A brief description of the tank is shown in table 1 .

Table 1. Tank characteristics according to operational documentation.

\begin{tabular}{|c|c|}
\hline Tank Parameters & Value \\
\hline Tank type & Vertical Welded Tank VST-20000 \\
\hline Volume, $\mathrm{m} 3$ & 19400 \\
\hline Height, mm & 11940 \\
\hline Tank apron ring diameter, $\mathrm{mm}$ & 45600 \\
\hline Maximum loading height, $\mathrm{mm}$ & 8700 \\
\hline Type of stored product & Oil \\
\hline Metal information & 09G2C \\
\hline Design & Standard Design № 704-1-60, \\
& Melnikov NIIPSK, Moscow \\
\hline Manufacturer & Novosibirsk Metal Tanks Plant \\
\hline Installation contractor & Bashnefteprovodstroy Mobile \\
& Mechanical Division \\
\hline Installation starting day & January 1988 \\
\hline Installation ending day & June 1988 \\
\hline
\end{tabular}

The choice of this tank is based on the fact that in operation the tank leaked through a crack formed on the sheet of the second wall ring. The crack layout is shown in fig. 1. A version of mismatch of the wall material with the designed one was taken as a hypothesis about possible causes of cracks of the tank second ring. To check this assumption, the cut pieces have been studied for determination of chemical composition and mechanical properties of the metal.

\section{Methods}

During the study the chemical composition and mechanical properties of steel such as tensile strength, yield strength, impact strength and hardness were evaluated.

In cutting fragments from the tank wall the following aspects were considered. The internal stresses of the first ring metal are greater than those of the second one, because the heights of the tank wall and the fluid affecting the first ring are bigger than the heights of the same parameters affecting the second ring. However, despite this, the crack formed in the second ring, not in the first one. It was therefore decided to compare the metal properties of the first and second rings. 


\section{TPACEE-2016}

For metallographic studies two fragments of the size of $750 \times 750 \mathrm{~mm}$. were taken from the tank wall. One fragment with a crack was taken from the second ring; the other, without cracks, was taken from the first ring.

To determine the chemical composition of steel of the first and second rings fragments of the tank wall the contents of the main elements was obtained.

Mechanical properties (tensile strength, yield strength and elongation) were determined on flat samples of type XV according to State Standard 6996-84. Tests were carried out on a tensile testing machine R-10 in accordance with State Standard 1497-84 and State Standard 7564-84.

\section{$14 \mathrm{VSW}$}

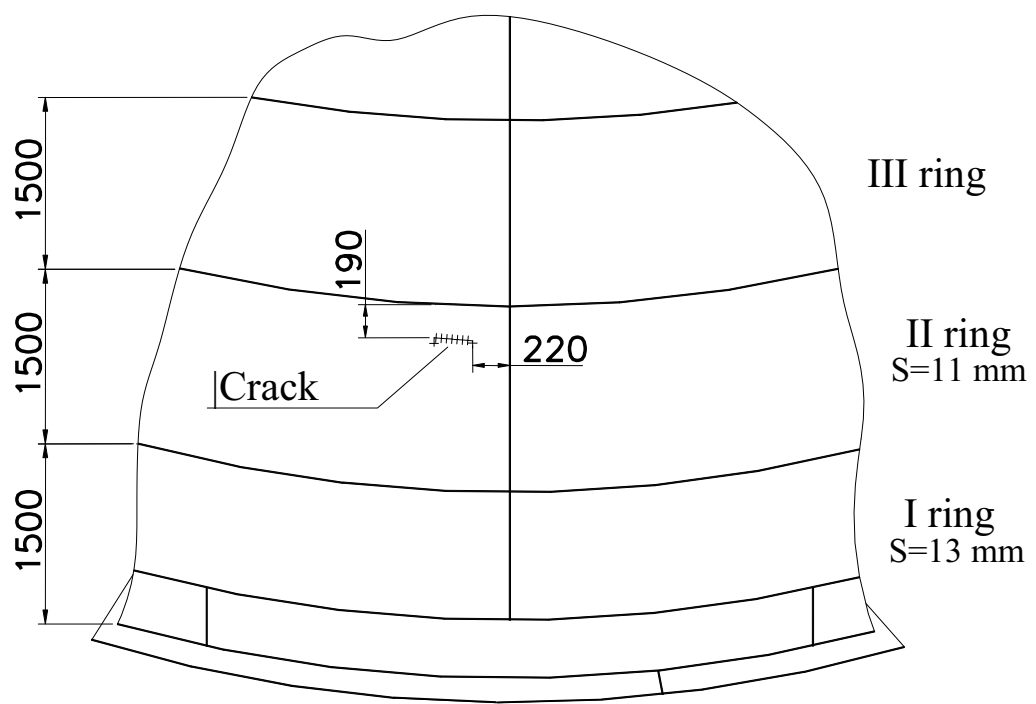

Fig.1 Crack layout on a tank wall.

The impact strength was determined on standard samples with size of $10 \times 10 \times 55 \mathrm{~mm}$ and U-shaped (sample VI) and V-shaped (model IX type) cuts according to State Standard 9454-84.

The type VI samples (Mesnager specimens) were tested at temperatures of $+20^{\circ} \mathrm{C}$ and $40^{\circ} \mathrm{C}$. The test purpose is to identify the compliance of the studied steels with State Standard 19282-84. The type IX samples (Charpy specimens) were tested at temperatures of $+20^{\circ} \mathrm{C},-5^{\circ} \mathrm{C}$ and $-40^{\circ} \mathrm{C}$. The temperatures of $+20^{\circ} \mathrm{C}$ and $-5^{\circ} \mathrm{C}$ were taken to determine the conformity of the studied steels to the requirements of Construction Rules and Regulations 2.05.06-85. The temperature of $-40^{\circ} \mathrm{C}$ was adopted with regard to the area of the tank construction. Tests were carried out on the Charpy Machine. Negative temperature was obtained by means of liquid nitrogen. Aviation kerosene was used as a cooling medium. The temperature was measured with a low-temperature thermometer with a scale division of $0.1{ }^{\circ} \mathrm{C}$. The tests were carried out in accordance with State Standard 9454-84.

The hardness measurement was carried out by the device TSH-2M with the diameter of the ball equal to $10 \mathrm{~mm}$ and the load $\mathrm{P}=30000 \mathrm{kN}$. The tests were carried out in accordance with State Standard 9012-84. 


\section{The Results and Discussion}

The chemical analysis showed that the first and second rings had been made of steel 09G2S. The chemical compositions of the steels of the first and second rings are shown in table 2. From the figure we can see that the carbon content in the metal of the second ring is significantly higher than the carbon content in the first ring. Moreover, the content of carbon in the second ring exceeds the values specified in State Standard 19281-89. However, the excess of the standard values are within the tolerance $- \pm 0.02 \%$.

Table 2. Chemical composition of the studied steels.

\begin{tabular}{|c|c|c|c|c|c|c|}
\hline \multirow{2}{*}{ Fragment } & \multicolumn{7}{|c|}{ Element content, \% } \\
\cline { 2 - 7 } & $\mathbf{C}$ & $\mathbf{S i}$ & $\mathbf{M n}$ & $\mathbf{C r}$ & $\mathbf{C u}$ & $\mathbf{~ N i}$ \\
\hline Ring I & 0.11 & 0.56 & 1.46 & 0.05 & 0.13 & 0.24 \\
\hline Ring II & 0.14 & 0.50 & 1.57 & 0.15 & 0.28 & 0.24 \\
\hline $\begin{array}{c}\text { Steel 09G2C } \\
\text { State Standart 19281-89 }\end{array}$ & $<0.12$ & $0.5-0.8$ & $1.3-1.7$ & $\leq 0.3$ & $\leq 0.3$ & $\leq 0.3$ \\
\hline
\end{tabular}

Fig. 2 shows a tensile diagram of the transverse specimens cut from the first and second rings. It can be seen that the sample cut from the first ring has a distinct yield plateau. The sample cut from the second ring practically misses a yield plateau.

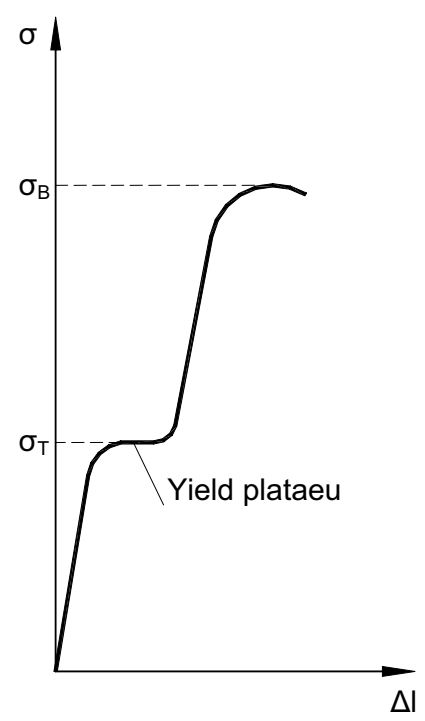

a) First Ring

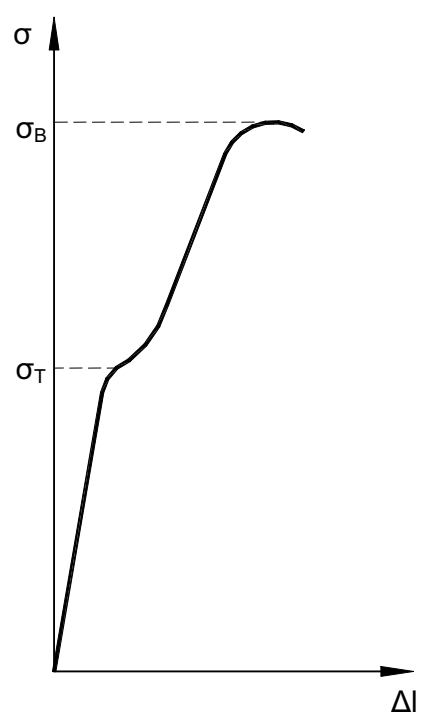

b) Second Ring

Fig.2 Qualitative tensile diagrams.

The results of the machine tensile diagrams processing are shown in Table 3; it also shows the values of the mechanical properties regulated by State Standard 19282-89. As shown in the table, the mechanical properties of the studied steels exceed the values regulated by State Standard 19282-89.

However, it should be noted that for the second ring the excess of the mechanical properties is significant. Such excess cannot be only stipulated by the fact that carbon content in the second ring is higher than in the first one. 
Table 3. Mechanical properties of the studied steels.

\begin{tabular}{|c|c|c|c|}
\hline Fragment & $\begin{array}{c}\text { Ultimate strength } \\
\boldsymbol{\sigma v}, \text { MPas }\end{array}$ & $\begin{array}{c}\text { Yield strength } \\
\boldsymbol{\sigma} \text {, MPas }\end{array}$ & Elongation $\boldsymbol{\delta}, \mathbf{\%}$ \\
\hline Ring I & 480 & 330 & 24 \\
\hline Ring II & 540 & 353 & 18 \\
\hline $\begin{array}{l}\text { Steel 09G2C State } \\
\text { Standard 19281-89 }\end{array}$ & 450 & 325 & 21 \\
\hline
\end{tabular}

Table 4 shows values of impact hardness for the examined steels at various temperatures. It also gives the values of impact hardness regulated by State Standard 19282-89. State Standard 19282-89 only provides data for samples with notch radius of 1 $\mathrm{mm}(\mathrm{KCU})$, because in metallurgy only these values are specified.

Table 4. Impact hardness of studied steels.

\begin{tabular}{|c|c|c|c|c|c|}
\hline \multirow{2}{*}{ Fragment } & \multicolumn{2}{|c|}{$\mathbf{K C U}[\mathbf{J} / \mathbf{c m} 2]$} & \multicolumn{3}{|c|}{ KCV [J/cm2] } \\
\cline { 2 - 6 } & $+\mathbf{2 0}^{\circ} \mathbf{C}$ & $\mathbf{- 4 0}{ }^{\circ} \mathbf{C}$ & $\mathbf{+ 2 0}^{\circ} \mathbf{C}$ & $\mathbf{- 5}^{\circ} \mathbf{C}$ & $\mathbf{- 4 0}^{\circ} \mathbf{C}$ \\
\hline Ring I & $100-105$ & $65-74$ & $83-86$ & - & $35-41$ \\
\hline Ring II & $57-60$ & $32-35$ & $46-51$ & $27-31$ & $14-18$ \\
\hline $\begin{array}{c}\text { Steel 09G2C State } \\
\text { Standard 19281-89 }\end{array}$ & $>59$ & $>39$ & - & - & - \\
\hline $\begin{array}{c}\text { Steel 09G2C SNIP } \\
\text { 2.05.06-85 }\end{array}$ & - & - & - & - & $\geq 29.4$ \\
\hline
\end{tabular}

$\mathrm{KCV}$ tests are tougher, as these samples have notch radius of $0.25 \mathrm{~mm}$. Therefore, these tests make it possible to more accurately identify the tendency of steels to brittle fracture. In this regard, builders and operators are more interested in the KCV values. Table 4 shows the KCV values regulated by SNIP 2.05.06-85.

As shown in Table 4, the KCU and KCV values for the first ring exceed the values regulated by normative documents. For the second ring the situation is different. At room temperature $\mathrm{KCU}$ can be considered as corresponding to State Standard. However, at temperature of $-40^{\circ} \mathrm{C}$ the impact hardness is below the normative values. KCU values differ slightly and KCV values differ significantly, almost twice.

Thus, it appears that the rings produced from the same grade of steel, have different properties. To find out what caused the difference in the properties, the hardness was measured. The results of hardness measurement are shown in Table 5.

Table 5. Steel hardness measurement results.

\begin{tabular}{|c|c|c|c|c|}
\hline \multirow{2}{*}{ Fragment } & \multicolumn{4}{|c|}{ Hardness value, HB, at measuring point } \\
\cline { 2 - 5 } & base metal & $\begin{array}{c}\text { in metal } \\
\text { bending area }\end{array}$ & $\begin{array}{c}\text { in heat-affected } \\
\text { base metal area }\end{array}$ & $\begin{array}{c}\text { welded channel } \\
\text { weld }\end{array}$ \\
\hline Ring I & 148 & 168 & 155 & - \\
\hline Ring II & 166 & 275 & 176 & 170 \\
\hline
\end{tabular}

As can be seen from the data shown in Table 5, the hardness value of the second ring is higher than the first. And the hardness value depends on the measuring point.

Thus, the deviation of the second ring top edge from the vertical may have contributed to the formation and further development of cracks. To prove this, an analysis of changes in the PBC-20000 tank wall radial movement caused by the operational load at different levels of loading was carried out [1]. It has been determined that in the area of the vertical site weld at the second ring level radial movements are maximal. They are caused by the initial imperfections of geometric shape of the tank wall in this area. This is where a crack formed, which together with the material properties data, gives evidence of fatigue fracture. To prevent the occurrence of similar failures it makes sense to implement a tank technical condition monitoring system [2-11]. 


\section{Conclusion}

The VST defects analysis showed that there is a change in metal properties [13,14,16-18]: strength, impact hardness and ductility, in particular. Thus, changing metal mechanical properties can be referred to as operational defects of tanks, used in hydrocarbon resource transportation.

The site of crack occurrence in the tank under test coincides with major wall deformation caused by operational load, which gives evidence of a more intensive development of fatigue processes in the tanks with imperfect geometry.

\section{References}

1. A. Pimnev, The development of methodology for assessment of imperfections in tanks geometry in technical diagnosis, Thesis of Candidate of Technical Sciences (TSOGU, Tyumen, 2006)

2. V. Kurushina, Yu. Zemenkov, WIT Transactions on Ecology and the Environment, 190, 2, 881-888 (2014)

3. V. Antip'ev, A. Nevolin, Yu. Zemenkov, Neftyanoe Khozyaistvo - Oil Industry, 10, 46-48 (1981)

4. Yu. Zemenkov, V. Shalay, M. Zemenkova, Procedia Engineering, 113, 254-258 (2015)

5. Yu. Zemenkov, V. Shalay, M. Zemenkova, Procedia Engineering, 113, 312-315 (2015)

6. E. Kurushina, V. Kurushina, Life Science Journal, 11(11), 517-521 (2014)

7. R. Mamadaliev, V. Kuskov, Yu. Zemenkov, A. Popova, Applied Mechanics and Materials, 770, 19-22 (2015)

8. A. Shabarov, A. Ibragimov, M. Zemenkova, S. Podorozhnikov, Gas industry, 12 (715), 50-54 (2014)

9. A. Pimnev, M. Zemenkova, Pipeline transport: theory and practice, 5 (51), 43-47 (2015)

10. M. Zemenkova, Yu. Zemenkov, A. Pimnev, V. Petryakov, Business magazine Neftegaz.RU, 11-12, 64-7 (2015).

11. A. Pimnev, M. Zemenkova, Fundamental researches, 11-2, 292-296 (2015)

12. A. Tarasenko, Deflected mode of tanks during repair works (Nedra, Moscow, 1999)

13. G. Hopersky, Research of the intense deformed condition of a wall of the tank at uneven rainfall of the basis, Thesis of Candidate of Technical Sciences (Tyumen, TSOGU, 1998)

14. M. Zemenkova, System monitoring of indicators of reliability of objects of pipeline transport, Dissertation of Candidate of Technical Sciences (TSOGU, Tyumen, 2007)

15. A. Votinov, Estimation of structural parameters of steel and resource characteristics of storage tanks in a continuous operation, Abstract of thesis of Candidate of Technical Science (KGTU, Krasnodar, 2006)

16. S. Stepanov, N., Cheremisin, S., Sokolov, A., Altunin, A., Shabarov, Computational method for relative permeability curves based on the Bernoulli generalized porous media equations, ECMOR 2012 - 13th European Conference on the Mathematics of Oil Recovery (2012)

17. R. Levitin, Yu. Zemenkov, Neftyanoe khozyaystvo - Oil Industry, 1, 110-114 (2016)

18. Ya. Gorelik, A. Shabarov, Yu. Sysoyev, Earth's Cryosphere, 12(1), 59 (2008)

19. I. Rozenshtein, Diagnostika materialov, 74(7), 48-51 (2008)

20. I. Kiryanov, S. Toropov, V. Toropov, Neftyanoe Khozyaystvo - Oil Industry, 8, 48 (2015)

21. I. Rozenshtein, Oil and Gas Territory, 10, 110-114 (2015) 